\section{REVISTA Mario Alario JURIDICA D'Filippo}

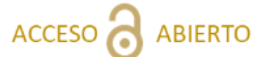

Para citaciones: Del Río Gonzalez, E., \& Luna Salas, F. (2021). El indicio: un problema epistemológico. Revista Jurídica Mario Alario D'Filippo, 13(26), 153-189.

https://doi.org/10.32997/2256-2796-vol.13num.26-2021-3619

Recibido: 17 de marzo de 2021

Aprobado: 10 de junio de 2021

Editor: Fernando Luna Salas. Universidad de Cartagena-Colombia.

\title{
El indicio: un problema epistemológico ${ }^{1}$
}

\author{
Epistemological problem of circumstantial evidence \\ Enrique del Río Gonzalez ${ }^{2}$ (D) Fernando Luna Salas ${ }^{3}$ ic \\ Universidad de Cartagena - Colombia
}

\section{RESUMEN}

Este artículo de carácter jurídico y de investigación, el cual se aborda desde una investigación cualitativa con revisión bibliográfica, tiene como objetivo primordial, describir y analizar los indicios como medios de prueba, desde un enfoque epistemológico y contemporáneo, rescatando su utilidad y existencia actual dentro de los procesos civiles y penales en Colombia.

Palabras clave: Indicios; prueba; presunción; razonamiento; verdad; epistemológico.

\begin{abstract}
This article of a legal and investigative nature is developed from a perspective of qualitative research based on bibliographical review and its primary objective is to describe and analyze the prima facie evidence as evidence, from an epistemological and contemporary approach, rescuing its utility and current existence within civil and criminal proceedings in Colombia.
\end{abstract}

Keywords: Evidence; proof; presumption; reasoning; truth; epistemological.

Copyright: (C) 2021 Del Río Gonzalez, E., \& Luna Salas, F. Este es un artículo de acceso abierto, distribuido bajo los términos de la licencia

https://creativecommons.org/licenses/by-nc$\mathrm{sa} / 4.0 /$ la cual permite el uso sin restricciones, distribución y reproducción en cualquier medio, siempre y cuando que el original, el autor y la fuente sean acreditados.

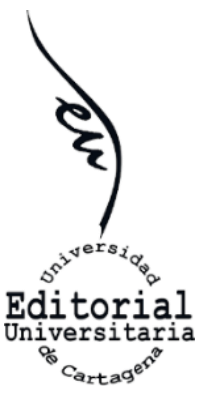

${ }^{1}$ El presente artículo es un extracto ajustado del libro denominado "La prueba indiciaria. Una mirada desde los sistemas procesales civil y penal”, publicado con el Grupo Editorial Ibáñez en el 2020.

${ }^{2}$ Magíster en Derecho y Doctor en Derecho (C) de la Universidad Sergio Arboleda. Profesor Investigador de las cátedras de Derecho Procesal Penal y Probatorio de la Universidad de Cartagena. Conjuez de la Sala Penal del Tribunal Superior de Cartagena y de la Sala Disciplinaria del Consejo Seccional de la Judicatura de Bolívar. enriquedelrio1975@ gmail.com

${ }^{3}$ Magíster en Derecho de la Universidad de Cartagena y Especialista en Derecho Procesal de la Universidad Libre. Profesor Investigador de las cátedras de Derecho Procesal y Probatorio de la Universidad de Cartagena. Editor de la Revista Jurídica Mario Alario D’ Filippo y Director del semillero de investigación Ciencia y Proceso. Miembro del Instituto Colombiano de Derecho Procesal - Capítulo Bolívar. flunas@unicartagena.edu.co 


\section{INTRODUCCIÓN}

Desde los griegos hasta la actualidad la idea de alcanzar la verdad, es decir, de poseer conocimientos válidos y absolutos, ha sido una de las máximas aspiraciones de la humanidad, lo que significa que las prácticas judiciales son formas empleadas por las distintas sociedades para definir las relaciones entre el individuo y la reconstrucción de la realidad (Foucault, 1983). Siendo así las cosas, el rol desempeñado por la prueba no tiene como finalidad asegurar la certeza de los enunciados fácticos expuestos, sino aportar razones para aceptar tales enunciados como un verdadero problema epistemológico (Ramírez, 2016).

Para algunos científicos sociales, el indicio visto desde esta perspectiva surge a finales del siglo XIX, instituyéndose como un método interpretativo basado en los datos reveladores de otros vestigios (Ginzburg, 1999)

Ahora bien, si de buscar la verdad se trata, es pertinente preguntarse si el paradigma indiciario resulta riguroso en la construcción de ese "conocimiento verdadero"; sobre todo frente a circunstancias punitivas en las que se ven afectados derechos fundamentales. Para Döhring (2008) con la ayuda de los indicios puede alcanzarse una verosimilitud más o menos cuestionable y algunas veces, la certeza respecto de un determinado punto.

El indicio se nutre de la construcción del silogismo, el cual es un tipo de argumento condicional, en el que el antecedente está formado por las dos premisas, unidas mediante la conjunción y el consecuente es la conclusión, en ese entendido, tanto las premisas como la conclusión son enunciados que incluyen al "todo" y "algún", con sus respectivos opuestos (García, 1982). Esta estructura se ve influida por el efecto atmósfera, consistente en que el razonamiento de los sujetos está influido por la impresión general que suscitan las premisas.

Para Aristóteles, el silogismo es una forma de razonamiento válido que posibilita proponer conclusiones luego de establecer determinadas premisas. La inferencia es válida con independencia de la verdad o falsedad de las premisas, pero la conclusión solo puede ser verdadera si las premisas son verdaderas (Cuadros, 2013).

Como se mencionó precedentemente, alcanzar la verdad sigue siendo uno de los mayores intereses humanos y reconocer la dualidad entre la verdad objetiva material y la verdad procesal formal, implica aceptar que ni los procedimientos, ni los jueces son infalibles, de allí que resulten necesarias unas prerrogativas para que la declaración de los hechos se aproxime a la verdad (Korakis, 2015).

En relación a ello, "los hechos para el proceso son conforme se han podido demostrar, y no como ocurrieron en la realidad, a su vez, la verdad dentro de 
un proceso es un objetivo difícil de satisfacer, a la cual se podrá llegar de acuerdo al grado de probabilidad o de confirmación que se tenga en relación con las proposiciones presentadas por las partes, por tal razón, frente al proceso lo que se tiene es una verdad con carácter de validez" (Carrillo y Luna, 2021, p. 173). De igual forma, es importante tener en cuenta, "que nunca se puede tener la certeza racional que una proposición es verdadera, lo que se puede conseguir dentro de un proceso y a través de los medios de prueba, es que se le atribuya un especifico grado de probabilidad o de confirmación de que un enunciado sea verdadero". (Carrillo y Luna, 2021, p. 206)

En ese sentido, el indicio se puede constituir como una verdadera garantía epistemológica, que, como los otros medios de prueba, tiene la pretensión de acreditar un hecho ventilado dentro de un proceso.

\section{Definición y caracterización del Indicio}

Existen tantas definiciones de indicio, como autores que escriben acerca del mismo. El profesor Devis (2012) resalta que la voz latina indicium es una derivación de indicare, que significa indicar, hacer conocer algo. Esta función la cumple el indicio en virtud de la relación lógica existente entre el hecho indicador y el hecho indicado.

Por su parte Muñoz (2016) estima que el indicio se conforma de una fuente material que puede ser cualquier elemento de la naturaleza capaz de sugerir en su perceptor una idea relacionada con el hecho que investiga; relaciones que pueden ser causales, de coexistencia o de sucesión. También hace referencia a la pluralidad de estos, explicando que se precipitan al proceso en cascada o en cadena cuando cada indicio tiene un iter atributo diferente al del otro indicio. el autor lo explica con un ejemplo, así:

"Por ejemplo, del hecho de comprar un individuo una bicicleta a un niño se infiere que es el padre natural no reconocido, y del hecho de que el piso que ocupa este señor lo adquirió poniéndolo a nombre de un pariente, se infiere que pretende evitar un embargo por impago de pensiones. No hay ninguna relación sintagmática entre la proposición "comprar una bicicleta" y "poner el piso a nombre de un pariente". Por eso hablamos de "cascada" porque cada indicio "cae por su cuenta" como los infinitos hilos de agua que la componen y se disuelven al fin en un mismo charco. En cambio, los indicios actúan en cadena cuando pertenecen al mismo tema y se refuerzan entre sí. Por ejemplo, el hecho de que se venda precipitadamente una casa (indicio Cerelatis) a muy bajo precio (indicio Ptretium vilis) a un amigo (indicio Affectio) y ante un notario que no es el del pueblo (indicio Ocultatio), conduce a inferir una pre construcción de insolvencia."

En la órbita procesal, los indicios son los signos, señales, rastros o huellas que permiten inferir que un acto pudo suceder, es decir, se constituye como toda 
acción relacionada con lo que se investiga, y que permite deducir su existencia y modalidades, de tal suerte, se puede definir como la circunstancia que sirve de base para presumir la existencia de otro hecho que se pretende conocer (Díaz de León, 2002).

A juicio del citado autor, el indicio es la representación de un hecho pasado y se incorpora al proceso para ser valorado como medio para probar lo que se indaga, no es solo la actividad intelectual de inferir o presumir, por lo tanto, no pertenece exclusivamente al campo de la mente, sino que atañe también al mundo fáctico.

De igual manera Parra (2005) sostiene que el indicio es un hecho especialmente cualificado del cual se infiere otro desconocido, en tanto que el mismo tiene la propiedad extraordinaria de salirse de sí mismo y mostrar otro, aspecto de especial utilidad procesal, cuando el resto de los medios de prueba disponibles requieren ilustración adicional.

Haciendo alusión a la analogía del rompecabezas, Zabaleta (2018) explica cómo se construye el indicio en materia procesal:

\begin{abstract}
$\mathrm{Al}$ inicio pueden encontrarse unas pocas piezas (indicios) que nos dan una vaga idea de cuál podría ser la imagen. Esa idea inicial nos sirve para buscar otras piezas que vayan encajando en el cuadro. Si es correcta, iremos sumando piezas y nos formaremos una mejor idea de cuál realmente es la imagen. Llegados a un punto, aunque no tengamos todas las piezas del rompecabezas, podemos ver qué figura contiene con bastante precisión. De igual manera, los indicios en su función heurística nos sirven para formarnos una idea de qué pudo haber ocurrido y, en consecuencia, formular una hipótesis que oriente la investigación. Si la hipótesis es correcta, probablemente, avancemos en la investigación y recojamos otros indicios, hasta llegar al punto que podamos justificar cómo ocurrieron los hechos del caso, sino todos, cuando menos los relevantes para resolverlos.
\end{abstract}

La Corte Suprema de Justicia, ha propuesto varias definiciones, entre las cuales se destaca la siguiente: “[...] (el) Indicio es toda huella, vestigio o circunstancia conocida o debidamente comprobada, susceptible de conducir a la mente, por vía de inferencia, al conocimiento de un hecho desconocido" (sala de casación civil, sentencia del 12 de marzo, 1974, publicada en Jurisprudencia y Doctrina Tomo III, No. 28)

De las diversas definiciones de indicio citadas se puede concluir que se trata de una prueba autónoma, trazada como una estrategia analítica para alcanzar el conocimiento o fijar los hechos en la inteligencia del juez, conformada por una estructura que parte de un hecho objetivo y acreditado (hecho indicador), el que se confronta con una regla de la experiencia, a través de una operación lógica- racional, para llegar a una conclusión. Esta última representa el hecho desconocido. Es necesario dejar claro que no se puede prescindir de ninguno 
de los elementos que conforman el indicio, ya que, si carece de uno de ellos, no se podría predicar que se configuró este medio de prueba.

\section{Autonomía del Indicio}

Al abordar el indicio, es necesario revisar su autonomía, especialmente de cara a las presunciones. La confusión, generalmente viene dada por la dificultad de distinguir entre la fuente de prueba (hecho comprobado) y el medio probatorio, ya que el hecho indicador del indicio hace parte de su esencia (Contreras, 2015).

Así, al hablar de la autonomía del indicio se comprende que este, si bien es de carácter indirecto, atípico, de carácter artificial y lógico presenta una total disimilitud con las presunciones. Autores como Manzini, citado por Muñoz (1997) sostienen que las presunciones son el resultado de una deducción y el indicio es el fruto de una inducción derivada de una regla de la experiencia.

Ampliando el concepto anterior, Framarino (2002), al explicar la naturaleza del raciocinio, establece que hay dos clases de prueba indirecta: indirecta por relación de identidad, dentro de la cual se encuentra la presunción; y prueba indirecta por relación de causalidad, en la cual enmarca el indicio. Luego establece que la diferencia entre ambos radica en que, mientras en la premisa mayor de la presunción siempre se encuentra una atribución de una cualidad a un sujeto, en la premisa menor del indicio se asigna una causa a un efecto.

No es posible excluir del recorrido teórico a Florián (2002) quien arguye que el indicio permite extraer un elemento concreto de un hecho o circunstancia, constituyéndose como una prueba indirecta, en cambio, la presunción es la conclusión de un razonamiento que parte de una premisa que, en ocasiones surge del curso natural de las cosas.

Un amplio sector de tratadistas considera que el indicio y la presunción son equivalentes, ya sea porque el indicio se considere un elemento de la presunción, o que se utilicen las acepciones como sinónimas, de acuerdo con eso Mittermaier (2005) propugna por su similitud, dado que, en su criterio al tratarse de pruebas artificiales, sus consecuencias arrojan deducciones de utilidad para el proceso, indistintamente del nombre que les asigne la academia.

En este orden Leone (1963) equiparando los conceptos aludidos manifiesta que la máxima expresión de las presunciones homini la ofrecen las pruebas indiciarias, las cuales tienen su mayor ámbito de aplicación en el proceso penal. Asimismo, Zavala (1989) reseña que el indicio hace parte de la presunción, en el supuesto de que se trata de una operación lógica mental que arroja conclusiones que surgen de un razonamiento reflexivo. 
Lessona (2006) concluye que las expresiones indicio y presunción son equivalentes sustancialmente y que se diferencian en la medida que el indicio, como sinónimo de hecho conocido, debe considerarse como causa, y la presunción, constituyéndose como el conocimiento del hecho antes ignorado, es el efecto.

Igualmente, Gorphe (2004) identifica estos conceptos, con la siguiente aseveración: "Entre el indicio y la presunción no se encuentra sino una diferencia de matiz, por referirse uno al caso concreto y la otra a una situación más general, pero desempeñan el mismo papel en la prueba".

Así también, el maestro Dellepiane (1997) puede ser incluido en esta perspectiva, tal como señala en su tratado:

¿Qué es una presunción legal ya sea juris et de jure, ya sea juris tantum? No es otra cosa que un mandato legislativo en el cual se ordena tener por establecido algún hecho, siempre que otro hecho indicador del primero, haya sido comprobado suficientemente. Por manera que una presunción cualquiera, no importa otra cosa que la prueba indiciaria impuesta por el legislador para la evidenciación legal de ciertos hechos.

Del mismo modo, Rocha (1990) define el indicio como una presunción no establecida por la ley, de tal manera que se presume de hecho al estar en presencia de circunstancias conocidas y probadas judicialmente.

Autores como Concha (1983) resaltan que la diferencia entre indicio y presunción se encuentra acentuada conforme a la rama del derecho en la cual se ejercite, es así como en materia criminal, las presunciones se llaman con más propiedad indicios y su importancia resulta, ante la inexistencia de otros medios probatorios para demostrar directamente la comisión de una conducta punible.

De todos los argumentos y tesis expuestas se concluye, que el grupo de doctrinantes que defienden la diferencia existente entre indicio y presunción, fundamentan su posición en la estructura del racionamiento mediante el cual se llega a cada uno de ellos. Por otro lado, quienes asemejan estos conceptos sustentan una posición muy pragmática, para facilitar el empleo de ambas acepciones en los estrados. En todo caso, se considera que la presunción es una forma determinada de razonar, mientras que el indicio es un hecho material. Es decir, el indicio es la prueba, y la presunción la consecuencia lógica que permite valorarla.

Es preciso resaltar que establecer la existencia o no de diferencias entre el indicio y la presunción es un ejercicio meramente dialéctico, que, en la realidad se reduce a una discusión académica, pues en criterio de los autores se trata de figuras jurídicas disímiles con diversa estructura en cuanto a sus requisitos y valoración. 


\section{Naturaleza de la prueba indiciaria}

La naturaleza de la prueba indiciaria es indirecta, compleja, circunstancial, y objetiva pues se basa sobre los hechos. También se le considera subjetiva y artificial, puesto que las circunstancias que se suscitan en la esfera psíquica deben ser apreciadas e interpretadas no sólo por la lógica sino también por la intuición del juzgador.

La prueba indiciaria es muy importante en todas las áreas del derecho por su connotación indirecta, puesto que mediante ella se pueden recrear hechos de difícil acreditación por otros medios probatorios. Sin duda alguna, es notoria la relevancia que se proclama de esta, puesto que no es posible dejar de lado fácilmente al indicio, dado lo primordial que puede traducir su intromisión dentro del proceso, cualquiera sea su naturaleza. En el ámbito penal, y dadas las circunstancias que en él se ventilan, tiene un uso especial y permanente, como quiera que el delincuente intenta no ser descubierto.

De igual forma, es relevante plasmar que la distinción entre prueba indirecta y directa para los efectos del ejercicio inferencial es inocua, como quiera que ambas clases de prueba requieren inferencias probatorias, como lo plantea González Lagier (2005):

La distinción entre prueba directa e indirecta es una cuestión de grado, que dependerá del número de inferencias que haya que realizar y del carácter más o menos evidente de las máximas de experiencia. Por ello, no habiendo diferencia cualitativa entre ambos tipos de prueba, se puede afirmar que los criterios de solidez rigen tanto para la prueba directa como para la indirecta.

Al momento de establecer la naturaleza jurídica de la prueba indiciaria, hay un sector dentro de la doctrina que le niega la calidad de medio de prueba autónomo y que, por el contrario, sostiene que es un objeto de prueba o una simple operación mental.

La vertiente que niega al indicio la condición de medio probatorio reduciéndolo al objeto de prueba es defendida por Dellepiane (1997), pues en la definición que propone de este lo delimita como: "todo rastro, vestigio, circunstancia, y todo hecho conocido, debidamente comprobado, susceptible de llevarnos por vía de inferencia, al conocimiento de otro hecho desconocido". Del anterior concepto es válido extractar que, a pesar de que el citado autor defiende en su tratado la autonomía de la prueba indiciaria, como se estudiará más adelante, la definición propuesta no es congruente con lo esbozado en su publicación.

Mittermaier (2005) puntualiza: "El indicio es un hecho que está en relación tan íntima con otro, que un juez llega del uno al otro por medio de una conclusión muy natural". Se entiende que, lejos de considerar al indicio como 
un medio de prueba, confunde el hecho indicador con la totalidad de la prueba indiciaria. Uno de los grandes tratadistas que reduce el indicio a un objeto de prueba es Florián (2002), quien expresamente sostiene:

El indicio puede considerarse desde dos puntos de vista: por un lado, se vincula al concepto de objeto de prueba y precisamente queda comprendido dentro del concepto de la prueba indirecta; y por otro, expresa el resultado de una operación mental, de una inducción lógica y psicológica, lo que desemboca en una apreciación y pertenece, consiguientemente a la valoración de la prueba, de la cual es uno de sus modos.

En este mismo grupo, es posible ubicar al profesor Roxin (2000), quien al definir el indicio lo cataloga como un objeto de prueba diciendo que: "Los indicios son hechos que permiten extraer una conclusión de un hecho directamente importante".

Los tratadistas mencionados no reconocen la autonomía del indicio como medio de prueba pues lo catalogan como objeto de prueba, y en algunos casos, lo asimilan a una forma de valoración. Estos criterios son restringidos y consideran una parte del indicio como un todo, desconociendo que la prueba indiciaria está compuesta por varios elementos que sincronizados generan la confiabilidad necesaria para constituirse de manera independiente. Esta postura es asumida por un grupo numeroso de estudiosos de la temática, como se referirá a continuación.

Arenas (2003) critica a los autores que reducen al indicio a un objeto de prueba, y reconoce que su construcción lógica está dirigida a demostrar otro hecho, por lo que se estructura como un medio probatorio particular $\mathrm{y}$ autónomo.

En palabras de Ellero (1953), el indicio como circunstancia probada perfecta o imperfectamente permite demostrar un hecho que se investiga. Esta imperfección no desdibuja su categoría de medio de prueba, por lo que, le corresponderá al juez determinar el grado de eficacia probatoria de los indicios que sean aducidos.

Esta discusión, según el enfoque de Rocha (1990), puede conciliarse si se reconoce que el indicio ostenta la dualidad de objeto de prueba y también de medio de prueba, conceptos que no se excluyen. En el caso de ser analizado desde la perspectiva de objeto de prueba, es por su aptitud de hecho en sí mismo considerado, sea que provenga del hombre o de la naturaleza, por lo que, debe ser probado para poder ser valorado.

Por otra parte, en su calidad de medio de prueba, suministra el conocimiento del hecho a demostrar, por lo tanto, dada la existencia de ciertas circunstancias debidamente comprobadas, el operador judicial desarrolla un 
razonamiento que parte de una probabilidad para adquirir convicción. Desde la misma perspectiva ecléctica, otros autores manifiestan que el indicio puede ser considerado un hecho, una inferencia lógica o todo el proceso de su construcción.

El criterio de los autores de este trabajo es que el indicio es un medio de prueba independiente y no una forma de valoración común a todos los medios probatorios. Tampoco podría considerarse el indicio como objeto de prueba, pues tal posición sería entender a la parte por el todo, pues, la inferencia racional, u operación mental, y el hecho indicador son elementos fundamentales del indicio, mas no lo representa como conjunto.

El indicio es un medio de prueba autónomo, derivado de conjugar el elemento material (Hecho indicador), el elemento psicológico (Inferencia racional), las reglas de la experiencia y la conclusión indiciaria.

\section{Clasificación de los Indicios}

La clasificación de indicios es prácticamente infinita pues van a existir tantos como situaciones fácticas se presenten, es así como ninguna codificación que se efectúe al respecto va a comprender su globalidad. Debido a la desconfianza en la valoración y el criterio del juzgador dentro del periodo conocido como exégesis, los antiguos juristas elaboraban, en consonancia con el sistema de tarifa legal, largas y minuciosas listas que tenían por finalidad guiar el criterio de los jueces.

En la actualidad, tales catálogos carecen de sentido, debido a que la valoración probatoria es libre y se encuentra enmarcada dentro del sistema de la sana crítica, no obstante, se enunciarán brevemente algunos puntos que conservan cierta utilidad práctica, principalmente en la academia, como es la disquisición entre indicios necesarios y contingentes. (Parra 2005).

Sea lo primero mencionar que los indicios necesarios se constituyen como aquellos que demuestran la existencia de un hecho, de manera inequívoca e indiscutible. De la anterior definición se colige que este tipo de indicios sólo se generan en la verificación de algunas leyes de la naturaleza, las cuales no responden a la voluntad humana, por ejemplo, aquellos relacionados con la física como lo sería la gravedad, teniendo en cuenta que, todo cuerpo arrojado al vacío, indefectiblemente, se detendrá al alcanzar el suelo. Por otro lado, los indicios contingentes no pueden ser encapsulados como verdades absolutas o irrefutables en la medida que, surgido un hecho, éste puede haber sido originado por distintas causas, o de una que produzca diversas consecuencias, tal como sucedería al encontrar a una persona al lado de un fallecido, se deberá en dicho caso no solo verificar la causa de la muerte y de ser violenta, descartar si efectivamente el señalado ocasionó la misma. 
En el proceso penal, los indicios son de carácter contingente, pues, cualquier hecho que pretenda aducirse, podrá responder a variados orígenes por lo que le corresponderá al funcionario descartar todas las posibilidades, y adoptar una decisión teniendo en cuenta el principio constitucional de presunción de inocencia, que impone la obligación de interpretar la situación en favor del imputado, siempre y cuando existan variedad de conclusiones con fuerza objetiva.

De acuerdo con esto, Tirado (2013) propone unas reglas que deben tener en cuenta los intervinientes para el manejo de indicios contingentes, que son la acreditación de la certeza, independencia y autonomía del hecho indicador, el concurso de hechos indicantes, la posibilidad de contradicción de estos elementos, la convergencia y concordancias de las inferencias, la gravedad del nexo causal entre el hecho indicador y el hecho indicado y finalmente la eliminación reflexiva del azar y la falsificación.

Según el referido tratadista, la aplicación de estas reglas garantiza la prevalencia de los derechos fundamentales de los intervinientes, pues delimita el margen de error en cada caso.

\section{Conformación de la prueba indiciaria}

Hay un sector de académicos que consideran que la estructura de la prueba indiciaria atiende al esquema lógico del silogismo, el cual cuenta con una premisa mayor, una premisa menor y una conclusión (Dellepiane 1997).

A juicio de Bueso (2001) la estructura del silogismo indiciario se construye con el siguiente esquema: a). Una premisa mayor fundada en la experiencia o en el sentido común; b). Una premisa menor, que atiende a la comprobación de un hecho; y c). Una conclusión, sacada de la referencia de la premisa menor a la premisa mayor.

El silogismo es entonces un juicio deductivo, por medio del cual, como consecuencia de dos premisas dadas, se infiere una nueva. Está conformado por tres estipulaciones, las cuales se sustentan en reflexiones independientes, que constituyen los fundamentos teóricos para obtener un resultado.

Se colige entonces que el indicio es una circunstancia cierta de la cual se puede obtener, por inducción lógica, una conclusión sobre el hecho desconocido, cuyo esclarecimiento se intenta.

Algunos importantes pensadores del derecho probatorio se apartan de la posibilidad de que el silogismo fundamente la operación indiciaria. Es así como Parra (2005) expresa:

No tiene el indicio estructura de silogismo; el indicio es un hecho que muestra otro. En todas las pruebas, como ya se ha dicho, es necesario 
para valorarlas tener en cuenta las reglas de la experiencia, las reglas técnicas, solo que en la prueba indiciaria estas reglas se utilizan antes para poder conseguir el hecho buscado; inclusive, la lógica formal solo es una parte de la lógica dialéctica. No se puede hacer abstracción de un hecho, quitarle todas sus circunstancias, dejarlo, por así decirlo, puro, tratarlo como silogismo y sostener que es un indicio. Tratar el indicio con los criterios de la lógica formal, es atentar contra la libertad de las personas. El indicio no es un hecho neutro, sino un hecho que por estar dentro de determinadas circunstancias muestra otro; de tal manera que el hecho indicio nunca es solo, sino siempre está circunstanciado.

Otros tratadistas consideran que la estructura indiciaria no puede asemejarse exactamente con el silogismo, reconociendo que el juzgador relaciona el hecho indicador con la regla de la experiencia, y ubicada esta última, la aplica al caso objeto de estudio.

El criterio anterior es compartido por Pabón (2007), quien manifiesta que, en materia criminal, no se puede analizar únicamente el indicio como una armazón estática y compleja de silogismo, pues de ser así se limitaría a la lógica, sin que se considerara en su construcción la conducta humana.

La última postura reseñada es la más cercana al criterio de los autores del presente trabajo, pues el proceso se constituye de un cúmulo de circunstancias relacionadas con el comportamiento de los individuos más allá de los criterios estrictos del método formal por lo que no puede arroparse el examen de los indicios como una simple categoría filosófica, alejada de la realidad. Si bien, puede optarse por construirse el indicio con la orientación de la estructura del silogismo para efectos prácticos, su valoración no puede encasillarse exclusivamente en cumplir las reglas que restringen su estructura.

La más reciente jurisprudencia de la Sala de Casación Penal de la Corte Suprema de Justicia, con relación a los criterios de sana crítica y su relación con los enunciados de probabilidad, ha señalado que para acreditar el carácter científico de una ley, tesis o enunciado, estos deben estar soportados en los principios de universalidad, síntesis, verificabilidad, y contrastabilidad; siendo el último la facultad de confrontar la teoría de la cual se predica cientificidad, con la experiencia, por eso, esta corporación indica que: "[...] es científico todo enunciado que sea contrastable con el mundo empírico, esto es, que haya sido confrontado mediante experimentos sin llegar a ser refutado". (Corte Suprema de Justicia, Sala de Casación Penal, sentencia SP1786-2018 de radicado No. 42631 del 23 de mayo de 2018, ponencia del magistrado Eugenio Fernández Carlier).

De esta manera, un enunciado probabilístico se iguala más a una regla de la experiencia que a una ley o tesis científica; y en aquellos casos en los que no puedan contemplarse como máxima de la experiencia, no es un imposible 
epistémico que las partes igual acudan a ellos, a modo de datos empíricos, para sustentar su teoría del caso.

\section{Elementos de la prueba indiciaria}

Para hablar acerca de los elementos del indicio, es importante recordar que este es un medio de prueba complejo, compuesto e indirecto, el cual permite la producción de una fuente probatoria que servirá para formar la convicción judicial, partiendo de un hecho conocido, que debe ser alegado y demostrado en el proceso, y que ha sido denominado "hecho indicador" o "indicante". Este, contiene un argumento de prueba que posibilita, por vía de inferencia inductiva, un juicio lógico que tiene su soporte en las reglas de la experiencia y los conocimientos científicos, para llegar al conocimiento de otro hecho desconocido, al cual suele denominársele "indicado", y que aportará al juzgador una fuente probatoria que podrá utilizar para comprobar el factum alegado dentro del proceso (Bello, 2016).

De la definición del indicio se puede concluir cuáles son los elementos que lo integran, por lo que se tiene que un indicio está conformado por un hecho indicante, un hecho indicado, una relación causal o nexo científico y una máxima de la experiencia aplicable al caso concreto. Los anteriores elementos, vistos como un todo compuesto y complejo permiten la construcción de este medio probatorio.

Con respecto al hecho conocido, indicador o indicante se precisa que este debe encontrarse plenamente probado dentro del proceso, ya que se constituye como el punto de partida de la indagación efectuada por el administrador de justicia, en tal tenor, su existencia debe ser fidedigna para que la búsqueda del hecho desconocido resulte consecuente (Azula, 1993).

Por su parte Fernández M. (2005) explica que la prueba indiciaria está formada por los llamados indicios o hechos base, de los cuales se esperan que primeramente sean fiables, por lo que se necesita que estén plenamente probados y así evitar que la prueba se construya sobre la base de meras sospechas. Pero, además, insiste en una pluralidad, esto es, que se disponga de varios datos probatorios y que todos ellos, tomados en su conjunto, conduzcan a una misma conclusión inculpatoria. (p. 258 y 259).

Luego de estos elementos objetivos, afirma el autor que el análisis debe extenderse a una relación de pertinencia, en el sentido de que, de un primer examen de cada uno de ellos, se desprenda que están relacionados con los hechos objeto de acusación, de modo que, tenidos en cuenta, pueden apoyar la conclusión judicial, la cual, sin duda, debe contener una máxima de experiencia. (p. 260 y 261) 
La importancia y ese carácter de racional de la máxima de experiencia encuentra su fundamento en que, si esta ostenta un gran grado de fiabilidad, necesariamente hay que tener por ciertos los indicios y, por ende, el hecho presumido. En este sentido, más que hablar de que ésta se encuentre probada, habrá que determinar si se encuentra o no asentada en conocimientos generales o en conocimientos científicos. (p. 261)

Asimismo, será necesario que no existan máximas de experiencia aplicables igualmente fundadas, esto es, que no sea posible alcanzar conclusiones alternativas que gocen de un mismo grado de probabilidad, pues, en caso contrario, bien podría entenderse que la hipótesis se apoya en meras sospechas. Y finalmente, es indispensable que la conclusión del razonamiento indiciario no entre en contradicción con otros hechos declarados probados. (p. 262 y 263)

Una de las características más importantes del hecho indicador es su capacidad para mostrar otro hecho más allá de sí mismo como fuente probatoria, así puede ser cualquier cosa, rastro, huella, vestigio, conducta, señal o actitud humana que servirá para el acreditamiento o verificación de los aspectos enunciados y debatidos en el proceso. (Bello, 2016). Este elemento solo adquiere importancia cuando al conjugarlo con los demás, construye una prueba indiciaria en la cual pueda descansar; y será irrelevante mientras no se encuentre la correspondiente regla de la experiencia para establecer el enlace en el orden del pensamiento.

El segundo de los requisitos es el hecho indicado y es aquel que se ignora pero que se espera llegar a conocer, el cual es el resultado final del todo que conforma el indicio; es justamente la fuente probatoria que se obtendrá al final de la inferencia inductiva del juicio lógico y crítico, basado en reglas de la lógica, experiencia y conocimientos científicos, partiendo del hecho indicante o indicador demostrado en el proceso, que aportará al juez la fuente probatoria que podrá utilizar para comprobar los hechos afirmados por las partes como fundamento de sus pretensiones.

El tercer componente de la prueba indiciaria se trata del nexo lógico o relación causal, que une el hecho indicador o indicante, con el hecho indicado. Este elemento consiste en el razonamiento o juicio lógico crítico, fundamentado en las reglas de la experiencia, en la lógica y en los conocimientos científicos, que mediante inferencias permiten arribar a la obtención del hecho desconocido, partiendo del hecho conocido y acreditado dentro del proceso. Esta es pieza principal de la prueba indiciaria, toda vez que conecta lo conocido con lo desconocido mediante un proceso mental que muchas veces no es de fácil construcción.

Los tres elementos mencionados deben ser auscultados a la luz de las reglas de la experiencia, determinantes para la construcción del indicio, las cuales 
cobran su plena materialización para cada caso concreto en la conclusión que se derive.

Sobre los elementos, y aterrizando al panorama práctico, es menester decir que muchos operadores judiciales se limitan a manifestar en sus providencias que "existen indicios" y no enuncian los elementos que permitieron la construcción de la prueba indiciaria, esto trae como consecuencia que no se conozca, por ejemplo, la regla de la experiencia utilizada para analizar los hechos, tanto indicante, como comprobado, complicando así la tarea del impugnante. O como en el ejemplo anterior, que no se tiene clara la máxima de la experiencia que sirve para realizar la inferencia, y se arriben a conclusiones desacertadas (Parra, 2005).

\section{Valoración del Indicio}

La operación indiciaria parte de un hecho cualificado del que se infiere otro desconocido y entre estos, media la regla de la experiencia y la inferencia razonable. De la definición acotada, surge como evidente el papel protagónico que juega el intérprete o quien efectúa la operación indiciaria o valoración del hecho indicante.

Es importante precisar que existe un doble proceso de evaluación, es decir, del ejercicio analítico para arribar a la conclusión indiciaria por un lado y por otro, la estimación que se le da al indicio en relación con la totalidad de las pruebas. En ambos procesos se requiere de un exhaustivo análisis mental, fundamentado en la sana crítica.

Houed Vega (2007), citando a Cafferata afirma que la valoración de una prueba es una operación intelectual destinada a establecer el poder suasorio de los elementos recibidos. Este concepto implica conocer el mecanismo para llegar a establecer qué valor tiene la prueba producida e incorporada al juicio.

El juez no puede valorar arbitrariamente el indicio. El legislador colombiano, dentro de los diferentes códigos procesales, ha establecido la forma de apreciarlos, es decir, en conjunto, teniendo en cuenta su gravedad, concordancia y convergencia, y su relación con los demás medios de prueba que obren en la actuación procesal. En todo caso, el juez, además de poseer la facultad de auscultar libremente la prueba, deberá ceñirse a los principios rectores de la normatividad aplicable, que son complementarios a los de la sana crítica probatoria, con el fin de asegurar que su valoración o ejercicio lógico va a estar sometido a unos mínimos que permitan afirmar que la conclusión a la que se ha llegado no es arbitraria.

De acuerdo a Luna (2018, p. 122) al hablar de valoración de la prueba, se hace referencia a la labor del juez, dígase que obligatoria, de realizar un análisis sobre el mérito de la convicción de la prueba, o como dice Gascón (2010, p. 
157) es un juicio de aceptabilidad de los resultados producidos por los medios de prueba, entendiendo estos últimos como todos los elementos probatorios aportados por las partes al proceso con el fin de crear en el juez una probabilidad de verdad en relación con los hechos objeto de controversia.

La razón de ser del indicio como medio de prueba, consiste en la posibilidad de que el juez infiera lógicamente de él, el hecho desconocido que investiga. Ejercicio que desarrolla partiendo de las reglas generales de la experiencia, del sentido común, y de los principios de la sana crítica probatoria, para lo cual deberá primero efectuar una crítica individual de los indicios y posteriormente confrontará la globalidad de las pruebas que se encuentren en el acervo probatorio (Londoño, 2006).

En todo caso, la efectividad, idoneidad y eficacia probatoria del indicio depende en gran medida de la prueba del hecho indiciario, para que la valoración efectuada por el juez, partiendo del silogismo sea provechosa, por lo tanto, se debe eliminar toda probabilidad de existencia de pruebas falsas o manipuladas por terceros.

Debe centrarse la importancia del indicio en la naturaleza de la operación mental, sin olvidar que este ejercicio se realiza igualmente con todos los medios probatorios. Framarino (2002), por ejemplo, puntualiza:

Los indicios, así como cualquier medio probatorio, son tenues hilos que constituyen el medio providencial que permiten conquistar lo desconocido, con su ayuda la inteligencia humana, partiendo de lo que conoce directamente, llega a lo que no puede percibir de modo directo.

Desde esta perspectiva, la valoración de la prueba indiciaria debe seguir una serie de pasos lógicos, sin ser una camisa de fuerza, orientados a optimizar la finalidad primordial de la prueba, consistente en la búsqueda de la verdad o de la mayor probabilidad de que un enunciado sea cierto. En este orden de ideas, quien realice la valoración debe iniciar por precisar la existencia y la fuerza de cada uno de los elementos del indicio. También debe establecerse la regla de la experiencia, y con ello, principalmente, el grado de aceptación de esta, dependiendo de su naturaleza.

Luego de la determinación de estos extremos, corresponde utilizar una valoración primaria que implica un esfuerzo lógico- racional que puede partir del hecho indicador, o de la regla de la experiencia, para finalmente lograr una conclusión. De esta manera, se llega al primer ciclo de valoración de la prueba indiciaria que es de carácter interno. Posteriormente, es necesario que se descarte que la conclusión indiciaria no sea el producto del azar o de la falsificación del hecho indicador.

El análisis o valoración debe hacerse de manera individual, para cada indicio, luego todos ellos e incluso el resto de las pruebas, deberán apreciarse 
conforme a las reglas de la sana crítica, por cuanto el indicio experimenta una doble evaluación. En la valoración final o en conjunto se tendrá en cuenta la gravedad, la concordancia y la convergencia de cada uno, y su relación con los medios de prueba que obren en el proceso.

Es posible que de la valoración individual y en conjunto se pueda calificar al indicio como grave, leve y levísimo, dependiendo de la contundencia demostrativa que ostente. Lo anterior de conformidad a lo que ha manifestado la Corte Suprema de Justicia:

La connotación de levedad o gravedad del indicio no corresponde a nada distinto al control de su seriedad y eficacia como medio de convicción que en ejercicio de la discrecionalidad reglada en la valoración probatoria realiza el juez, quien después de contemplar todas las hipótesis confirmantes e infirmantes de la deducción establece jerarquías según el grado de aproximación a la certeza que brinde el indicio, sin que ello pueda confundirse con una tarifa de valoración preestablecida por el legislador.

Se trata de una simple ponderación lógica que permite al funcionario judicial asignar el calificativo de grave o vehemente al indicio contingente cuando el hecho indicante se perfila como la causa más probable del hecho indicado; de leve, cuando se revela sólo como una entre varias causas probables, y podrá darle la menguada categoría de levísimo cuando deviene apenas como una causa posible del hecho indicado. (Corte Suprema de Justicia, Sala de Casación Penal, Rad. 9858 del 4 de mayo de 1997, con ponencia del magistrado Jorge Aníbal Gómez Gallego).

Es lógico que en el proceso de valoración indiciaria el razonamiento sea más analítico, dado que este medio probatorio no puede ser considerado un hecho cualquiera, sino que se constituye como aquel que tiene la propiedad de mostrar otro. La delicadeza de ese proceso argumentativo implica desterrar en la práctica errores en su construcción sea por omisión de alguno de sus elementos, o porque se referencien de manera confusa o inadecuada, lo que generará un detrimento al principio de publicidad, contradicción, y en general, el derecho a la defensa y al debido proceso, como quiera que no habrá opción de controvertir adecuadamente lo que se desconoce. El profesor Reyes Alvarado (1989) lo describe así:

Cuando el funcionario judicial calla la forma como el indicio se construyó, no solamente dificulta precisar si se dio o no cumplimiento al principio de legalidad de la prueba, sino que está vulnerando también el principio de publicidad en cuanto las partes no saben qué clase de indicio se ha creado ni si ha sido correctamente construido, y se incumple así mismo el principio de controversia ya que sin conocer la estructura misma del indicio construido, las posibilidades de refutar su creación y valoración disminuyen notablemente; en efecto, si solo sé que en mi contra existe un indicio de oportunidad, pero desconozco el 
hecho indicador manejado por el juez, o no está clara la regla de la experiencia por él empleada, no estaré en posibilidad de discutir si es un medio de prueba correctamente creado y si su valoración es adecuada; esos juicios de valor solo los podré emitir si el funcionario judicial ha señalado expresamente qué elementos ha tomado para la construcción del indicio. Esa violación a los principios de publicidad, controversia y legalidad de la prueba supone entonces un grave detrimento al derecho de defensa, lo que a su vez significa desconocimiento del mandato constitucional del debido proceso.

Resulta claro entonces que el funcionario judicial tiene el deber de precisar cada uno de los elementos de la prueba indiciaria. Vale decir que la controversia puede dirigirse a cualquiera de estos aspectos, es decir, al hecho indicador, a la regla de la experiencia, a la inferencia racional o a la conclusión. Se trae a colación, de cara a lo manifestado, lo dicho por la Sala Penal de la Corte Suprema de Justicia, referido a un asunto tramitado dentro de la ritualidad de la ley 600 de 2000, en el que se hace referencia al manejo de la prueba circunstancial. Concretamente un magistrado disidente en el salvamento de voto critica la forma en que la sala mayoritaria determina la existencia de indicios de responsabilidad sin una adecuada construcción:

De tal suerte que, a la hora de construir un indicio, con lo primero que hay que contar es con un hecho indicador debidamente probado, lo que implica que es necesario señalar cuáles son las pruebas de ese hecho indicador y qué valor se le confiere a las mismas. Pues si no se cuenta con pruebas del hecho indicador, o existiendo no se les da credibilidad, obviamente no puede declararse probado el hecho y, por ende, tampoco puede intentarse la construcción de ningún indicio (Corte Suprema de Justicia, Sala de Casación Penal, sentencia No. 33837 del 18 de marzo de 2015, con ponencia del magistrado Eugenio Fernández Carlier, con salvamento de voto del magistrado José Leonidas Bustos Martínez).

Probado el hecho indicador, el segundo paso es señalar la regla de la experiencia. Este peldaño no puede omitirse, puesto que de esto va a depender, en buena medida, el carácter o fuerza probatoria del indicio. Además, dado que la regla de la experiencia eventualmente usada puede ser falsa, inexacta o tomada con un alcance diferente al que realmente tiene, es indispensable que se exprese para que pueda ser controvertida y de esa forma garantizar adecuadamente el derecho a la defensa.

Fijado lo antedicho, el tercer paso será enunciar el hecho indicado, cuyo grado de asentimiento dependerá, como ya se indicó, del alcance de la regla de la experiencia. Por último, se debe valorar el hecho indicado, en concreto y en conjunto con los demás medios probatorios, para concluir qué se declara probado.

Indudablemente la postura vertida en el salvamento de voto citado es acertada en cuanto a la forma de conformación de la prueba indiciaria y, además, en lo 
que hace referencia a la obligación que tiene el dispensador judicial de cumplir con esta ritualidad, la cual es necesaria para facilitar el ejercicio del derecho de contradicción y de defensa, además se constituye en un modo adecuado de hacer transparente el proceso de valoración probatoria.

\section{Errores probatorios derivados del Indicio}

Los errores probatorios derivados de la interpretación y valoración de los indicios usualmente no se generan en el plano de las estructuras lógicas o teóricas sino en el de la práctica judicial. El poder suasorio del indicio como medio de prueba es extraordinariamente variado y depende de la sagacidad del intérprete y de su análisis. A pesar de los avances científicos, no se desconoce que abundan indicios poco concluyentes, que la inducción o la deducción lógica son conceptos de carácter filosófico a los que solamente se realizan aproximaciones y que generalmente faltan eslabones en la cadena de razonamiento para que se excluya la hipótesis del error.

Buena parte de la doctrina, especialmente la anglosajona, se guía bajo la proposición de que "los hechos no mienten"; de allí que los indicios posean una fuerza probatoria poderosa, empero es indispensable conservar su manejo aséptico, pues pueden ser artificiosamente preparados para llevar por cauces equivocados la acción de la justicia. Gracias al sistema de la libre convicción imperante, han desaparecido algunas de las reglas restrictivas de la valoración probatoria del indicio suscitando que su fuerza persuasiva dependa de la relación que estos tengan con respecto al hecho que necesita ser acreditado. (González, 2011).

Para Garraud citado por Gorphe (2004), los errores judiciales surgidos con ocasión a la aplicación de este medio de prueba se derivan tanto de la comprobación del hecho indicador como de la defectuosa interpretación del operador judicial. Igualmente, siempre existe la posibilidad de que se presenten errores en cualquier etapa del proceso de construcción y valoración probatoria.

En consecuencia, el hecho indicante debe estar plenamente probado a través de los medios de pruebas legales, para que la construcción del indicio pueda ser válida. En cada caso, y dependiendo de la premisa mayor, la conclusión o el hecho indicado debe ser preciso y claro. Para que se materialice esta declaración de suficiencia deben ser descartados el azar y la falsificación de prueba. Estos se constituyen en las más grandes fuentes de errores de esta prueba indirecta, ya que la conexión del hecho indicador con la regla de la experiencia y la conclusión no puede ser obra de la casualidad o contingencia y mucho menos, puede estar forzada por la intervención de un tercero que tergiversa el hecho generador (Silva, 2002). 
Por ejemplo, las primeras inspecciones, en relación con el lugar donde los hechos se perpetraron, son decisivas para la investigación criminal, y cualquier negligencia en estos momentos puede determinar la desaparición de los indicios más próximos. Luego de estas pesquisas le corresponde al operador judicial, la labor de interpretar los hechos recopilados para determinar su alcance.

En cuanto a la necesidad de descartar el azar y la proscripción de la falsificación de la prueba, es menester definir al primer concepto como todo hecho excepcional, contrario a lo que es regular, constante o predecible. Se precisa como el encuentro de una serie de causas extrañas sin previa correlación, como lo explica el maestro Dellepiane (1997).

Este mismo autor considera que existen diversos grados de azar, en la medida que mientras más grande sea el alejamiento de dos series fenoménicas independientes, más improbable será el encuentro entre las mismas, lo cual en materia de valoración de la prueba indiciaria se traduce en que, en la práctica, solo en casos aislados este fenómeno podría hacer confluir varias coincidencias.

En términos prácticos, las conclusiones lógicas pueden ser equivocadas porque la conexión de la operación indiciaria se genera por el azar. Así, por ejemplo; un transeúnte se encuentra fumando un cigarrillo, dejando sus muestras de ADN en él, al terminar lo lanza, la brisa lo conduce hacia una edificación cercana en donde se encuentra el cuerpo de una persona que horas antes fue asesinada. Al realizar la investigación y recuperar los restos del cigarrillo y el ADN presente, esto indicará la presencia del desprevenido sujeto en el lugar de los hechos. La apreciación, en tal sentido, no es impropia por su apego a la lógica y a la racionalidad. Este yerro se despejará en la medida que aparezcan otras pruebas que desvirtúen la primera conclusión.

Otra de las razones que puede inducir al funcionario judicial al error, es la falsificación de la prueba; que consiste en configurar fraudulentamente el hecho indicador, o de la prueba necesaria para que se conforme el indicio. El falsificador, por lo tanto, tiene como finalidad, conducir al investigador a una conclusión diferente de la verdad. De esta posibilidad de equivocación, solo se puede alejar el juez mediante una amplia y rigurosa ponderación de infirmantes y contraindicios, y de una rigurosa y exigente actividad verificadora de la concordancia de los indicios entre sí (Arenas, 2003).

Una clara ilustración de falsificación de la prueba es una de las escenas de la tragedia Otelo de William Shakespeare, en la cual Yago, además de insinuaciones, para aumentar los celos de Otelo, logra colocar el pañuelo de su pareja en manos del supuesto amante, el marido iracundo, quien sufre un ataque, acaba matándola, basándose en los hechos que Yago le ha hecho creer, cuando es él quien se encarga de construir todo un escenario falso: 
Yago: Veo señor que la intranquilidad no os deja vivir. Siento haber sido yo quien os lo haya tenido que decir. ¿Queréis una prueba?

Otelo: ¡Que si yo quiero una prueba! Sí, eso es lo que quiero.

Yago: Claro que podéis; pero ¿cómo? ¿Quisierais, tal vez, gozar de este espectáculo, señor? ¿Quisierais vos, como un espectador sorprendido, tener que contemplar cómo otro hombre la cabalga?

Otelo: ¡Oh! ¡Esto es la muerte y la condenación eterna!

Yago: No es cosa fácil, y tampoco creo que fuera muy edificante sorprenderlos en su momento. ¡Dios no quiera que otros ojos que los suyos sean testigo de cómo se acuestan!

¿Qué hacer entonces? ¿Cómo actuar? ¿Qué puedo deciros?,

¿Dónde encontrar las pruebas? No es posible ver la cosa. Ni la pasión de un momento, ni la imprudencia, ni la tontería dan ocasión para ello; por más que estén calientes como monos, o perras salidas, o lobos en celo. Sin

embargo, yo os puedo decir que, si los hechos se evidencian y las circunstancias los confirman, bien podréis convenceros de toda la verdad.

Otelo: ¡Dame hechos que sean reales y evidentes!

Yago: No es éste un oficio que sea de mi agrado; pero, ya que, deseoso de cumplir debidamente con los deberes de la amistad y de la honradez, me he metido en este asunto, iré aún más lejos. Estaba yo acostado ayer noche con Cassio, y como me dolían las muelas y no me dejaban dormir, me di cuenta de que hay ciertos hombres que se van fuera de traste y que ni durmiendo tienen frenillo en la lengua. Uno de tales es Cassio. Y en suelos decía: < ¡Mi bella Desdémona, es preciso ser prudentes; que no descubran nuestros amores!> y entonces, señor, me tomaba la mano y me la apretaba dulcemente, diciéndome; < ¡Oh, amor mío!> y luego se abrazaba a mí, pidiéndome besos que yo no podía darle. Después, echándose sobre mí, con su pierna en mi cadera, suspiraba y besaba. Y oí que decía: < ¡Mal haya el destino que te ha hecho mujer del moro!>

Otelo: ¡Oh, esto es monstruoso! ¡Más que monstruoso! Yago: ¡Bah, sólo era en sueños!

Otelo: Sí, aunque sólo era en sueños, es una prueba evidente que muestra un hecho irrefutable.

Yago: También puede ayudar a confirmar otros hechos que de por sí carecen de importancia.

Otelo: ¡La haré pedazos!

Yago: Bien, pero no os precipitéis. Todo ello no prueba nada. Puede que sea una mujer honrada. Escuchadme ¿Podríais decirme si en alguna ocasión habéis visto en manos de vuestra esposa un pañuelo con unos bordados salpicados de fresas?

Otelo: Yo le ofrecí uno muy parecido en una ocasión; fue mi primer regalo. Yago: No lo sabía; pero hoy he visto un pañuelo igual a ése en manos de Cassio; se limpiaba la barba; estoy seguro de que era el de vuestra esposa. Otelo: Bien puede ser que fuera ése...

Yago: Tanto si es ése, como si fuera otro cualquiera que hubiese sido suyo, es un indicio que hacer pensar.

Otelo: ¡Oh!... ¡ Y por qué el miserable no ha tener cien vidas!, ¡ Una sola es demasiado poco, es demasiada poca cosa para satisfacer toda mi venganza! ¡Bien contemplo ahora que todo es verdad! ...Escúchame, Yago, ¡Todo mi gran amor, mi dicha y mi felicidad se la ha llevado el demonio! ¡Se ha ido al infierno! ¡Dios de la venganza, levántate, y sal de lo hondo del infierno! 
¡Y tú, oh, amor! Que reinabas en mi corazón, cede tu puesto al odio que nos hace esclavos. ¡Que mi alma se llene de odio, y cien mil diablos me lleven a la venganza! Yago: Esperad, aún...

Otelo: ¡Oh, necesito matar...matar...! (Shakespeare, 2000).

Este ejemplo de la falsificación de la prueba es más común de lo que se podría creer. La equivocación está latente al momento de juzgar, pues se necesitaría de poderosos contraindicios y extrema verificación de todos los medios de conocimientos para no caer en yerros, como lo relata Devis (2012).

El mayor o menor número de hechos indiciarios no limita la posibilidad de que se genere una falsedad, pues puede incluso suceder que se adultere un grupo de hechos, por tal razón, cada evento requiere un examen individual y luego en conjunto de las pruebas allegadas para lograr el mayor grado de convencimiento.

Para excluir la hipótesis del azar y de la falsificación de la prueba, el maestro Dellepiane (1997) propone que la información suministrada por cada rastro recogido debe ser verificada y precisada a través de una compleja labor, para efectos de corroborar las inferencias que de ellas se deduzcan.

La labor de comprobación implica acreditar mediante la utilización de diversas evidencias el hecho indicado y someterlo a un juicio analítico que aclare las posibles dudas, corroborando la inferencia existente.

Otro error que se presenta con frecuencia dentro del proceso de valoración judicial consiste en considerar que el indicio es una prueba incompleta, esta última, como reconoce Arenas (2003) limita el hecho que procesalmente se pretende acreditar.

Desde esta perspectiva, no existe diferencia entre el indicio y los demás medios de prueba: por ejemplo, un testimonio que reúna todos los requisitos legales y procesales puede tornarse suficiente para dar probado un hecho investigado, lo mismo que un indicio podría hacerlo. Pero si el medio de prueba aducido presenta fallas de cualquier orden, el juez bien puede restarle capacidad suasoria y declarar que en sí mismo no es suficiente para probar la circunstancia que se investiga. Similar conclusión podrá sacarse de un indicio o de una pluralidad de indicios contingentes.

Lo que resulta lamentable en la doctrina y en la práctica judicial, es la absurda equiparación que se hace entre el concepto de prueba incompleta y el indicio. Es común considerar que un medio de prueba no idóneo e insuficiente degenera indefectiblemente en una "prueba incompleta" y, por otra parte, entender que toda "prueba incompleta" es un indicio. Por esta vía se ha convertido al indicio en una especie de pretexto, debido a que, mediante esta práctica se valoran o disfrazan como indicios elementos que poseen vicios 
intrínsecos y que, por tal razón, no pueden ser tenidos como medios de prueba específicos y autónomos.

No son pocos los casos en los que el juez, no puede estimar una prueba, por ejemplo, un testimonio por vicios de forma o de fondo, y por ello decida tenerlo como indicio. Esa forma de proceder es contraria al manejo de los medios probatorios, pues desconoce las reglas esenciales del proceso y los principios de la sana crítica probatoria. Si la ley determina las condiciones de existencia y de eficacia de un medio de prueba, faltando estas, se desencadenarán las consecuencias pertinentes, según el caso.

Para evitar los errores dentro de la valoración probatoria también debe ser examinada la prueba que pueda debilitar u oponerse al indicio. Hay quienes llaman a estas circunstancias contraindicios, por consiguiente, el significado natural o recto del indicio puede ser desvirtuado de varios modos: por un lado, las conclusiones igualmente predicables del mismo hecho indicador, o de ese hecho en conexión con otros. Así, por ejemplo, la amenaza previa puede señalar al autor del daño, pero no siempre implica intenciones serias de cumplirlo, pues la enemistad entre la víctima y el supuesto agresor pudo haber cesado mucho tiempo atrás.

Aunado a lo anterior, no debe dejarse a un lado la evaluación de validez del indicio, por lo que, además del acatamiento de los requisitos antes expuestos se hace prudente que el juzgador cumpla con las siguientes pautas:

1. Que las pruebas del hecho indicador o indiciario hayan sido decretadas, practicadas, presentadas y admitidas, en forma legal.

2. Que no se hayan utilizado pruebas ilícitas o prohibidas por la ley, para demostrar el hecho indicador.

3. Que no exista una nulidad del proceso, que vicie las pruebas del hecho indicador.

4. Que la ley no prohíba investigar el hecho indicador o el indicado.

Estos parámetros son primordiales para evitar errores judiciales, ya que una decisión cimentada en la valoración de la prueba indiciaria, sin que se hubiera descartado las hipótesis del azar o la falsificación, implica más que un desgaste del aparato jurisdiccional respectivo, genera igualmente una vulneración a los derechos fundamentales del procesado, en la medida que se estaría decidiendo su situación jurídica con base en pruebas indebidamente conformadas, asemejadas a indicios como consecuencia de sus falencias, lo que de contera, choca con la naturaleza garantista del proceso penal.

\section{EI Indicio en el Ordenamiento Civil Colombiano}

La ley 1564 de 2012 mantiene la misma reglamentación que existía en el Código de Procedimiento Civil, hoy derogado, en lo atinente a al indicio, tal 
como se evidencia en los artículos 240 al 242 del Código General del Proceso que no difieren de los artículos 248 al 250 de la normatividad anterior.

Vale decir que se encuentra en el artículo 280 del CGP, una importante innovación en materia de prueba indiciaria, que agregó a los requisitos de la sentencia: "el juez siempre deberá calificar la conducta procesal de las partes $\mathrm{y}$, de ser el caso, deducir indicios de ella". Es decir, el administrador de justicia dentro del transcurrir de un proceso podrá encontrar elementos de convicción en la actuación de los intervinientes, situación que también está regulada en el artículo 241 del CGP.

El legislador estableció ciertas conductas procesales que deben ser consideradas por el juez como indicios, entre las que se encuentran:

- Art. 205 inc. 3 CGP: inasistencia de la parte a la audiencia, en la medida en que las preguntas no sean asertivas ni se refieran a hechos susceptibles de confesión.

- Art. 225 inc. 2 CGP: la falta de documento o de un principio de prueba por escrito.

- Art. 233 CGP: la falta de colaboración de una de las partes con el perito.

- Art. 238 \# 2 CGP: cuando una de las partes impide u obstaculiza la práctica de la inspección judicial decretada de oficio.

- Art. 267 CGP: oposición injustificada a exhibir documentos.

La reglamentación anterior por parte del legislador se hace pertinente en la medida en que ciertas conductas procesales de las partes pueden conllevar a la afectación en la obtención de elementos de prueba necesarios para resolver la causa litigiosa, constituyéndose así, en una forma de control jurídico sobre el debate probatorio.

En relación con este tema, y parafraseando al profesor Muñoz Sabaté (1997) se plantea que, al valorar la conducta procesal de las partes, se establece la necesidad de diferenciar axiológicamente los juicios éticos y los pragmáticos, considerando que son los segundos los que importan al proceso desde el punto de vista probatorio. Este autor manifiesta:

La conducta que siguen las partes dentro del proceso puede convertirse también en un dato indiciario sobre el cual basar la inferencia heurística, pero no tanto en virtud de consideraciones éticas que impongan como castigo o premio determinadas admisiones, sino apoyándose en argumentos lógicos cuyo sustrato experimental radica en el instinto de conservación y en un orden de ideas semejante al que legitima la aplicación procesal de los principios nemo tenetur o contra se pronuntiatio.

Por otro lado, dentro de los artículos 240, 241 y 242 se encuentra reconocido el indicio como un medio autónomo y se regula de manera clara los requisitos 
que deben cumplirse, y los parámetros de apreciación judicial respectivos. Es así como en desarrollo de este articulado, la Corte Suprema de Justicia en su Sala de Casación Civil ha analizado este tópico reconociendo su naturaleza y autonomía.

Se hace mención de la sentencia del 11 de diciembre de 2018 en la cual la Sala de Casación Civil de la Corte Suprema de Justicia recordó:

[e]1 indicio presenta una estructura lógica que consiste en un razonamiento que parte de una premisa especial (el hecho probado), para arribar a una conclusión hipotética (el hecho desconocido), a la cual se llega gracias a una regla de la experiencia (altamente probable), que es la que le otorga un amplio margen de convicción, dentro de los parámetros de lo razonable y de lo que la cotidianidad revela.

El fundamento de las reglas de la experiencia está constituido por la constancia que se observa en una relación de causa a efecto, es decir por la costumbre que se tiene en una serie causal. De ahí que el valor racional de la inferencia indiciaria es siempre de probabilidad, pues basta un solo hecho que refute o contradiga el enunciado que se cree verdadero, para que se vea mermado el grado de confianza que en él se tiene, por lo cual es posible concebir hipótesis indiciarias que suelen alcanzar el carácter de concluyentes al estar más allá de todo margen de duda razonable porque las máximas de la experiencia les otorgan un alto grado de convicción.

En nuestro Código de Procedimiento Civil, basta que se cumplan los requisitos que establecen los artículos 248 y 250 para que se tenga como legalmente eficaz una prueba indiciaria. El primero de ellos, como ya se dijo, exige la demostración del hecho indicador, mientras que el segundo señala las condiciones mínimas que debe reunir la inferencia racional que realiza el juzgador y su relación con los demás medios de prueba.

La tercera exigencia que estatuye la ley es la convergencia, radica en que los hechos conocidos y catalogados como indicios guarden armonía con el hecho principal que se investiga.

Todos estos patrones de validez formal y verdad material que le dan rigor o fuerza demostrativa al indicio, son observados, en la mayoría de los casos, de modo natural por el juez de genio aguzado, quien no necesita tener profundos conocimientos teóricos de tales asuntos para poder llegar a la correcta elaboración de tales inferencias, pues su ingenio y preparación jurídica le bastan para darse cuenta de si una conclusión de esa naturaleza es concluyente o, por el contrario, poco probable o contraevidente. (Sentencia de la Sala de Casación Civil de la Corte Suprema de justicia, Magistrado Ponente, Octavio Augusto Tejeiro Duque, Sc5418-2018, Radicación Nº 05042-31-84-001-200200107-01, Bogotá D.C., 11 de diciembre de 2018). 
De igual forma, es conveniente realizar un paralelo del manejo del indicio en materia civil y en materia penal, para precisar que mientras en los procesos civiles de simulación la prueba indiciaria se considera vital, en los asuntos penales se ha ido diluyendo su aceptación.

Este estudio no tiene como pretensión criticar la postura de la Sala de Casación Civil de la Corte Suprema de Justicia sobre el particular, sino que busca enunciar y describir el reconocimiento que se le ha dado a la prueba indiciaria, especialmente en lo relacionado con los procesos de simulación, a efectos de demostrar que la misma Corporación reconoce el amplio margen probatorio de las pruebas indirectas en materia civil, y su autonomía, pero le restringe su operación en materia penal, limitándola a una simple forma común de valorar todas las pruebas.

La referencia realizada sobre la prueba indiciaria civil, y en especial en materia de simulación tiene como finalidad primordial resaltar la gran utilidad que este medio de prueba ofrece dentro del derecho privado. Por lo tanto, no es de buen recibo que se le niegue la calidad de medio probatorio al indicio en materia penal, pues, la actividad probatoria no debe tener ninguna distinción, dada la finalidad de llevar la fijación de los hechos al juez, en razón del tipo de proceso, por cuanto es similar cuando se intenta acreditar unos hechos relevantes, tanto en materia penal como en el ámbito civil.

Resulta contraproducente que el indicio sea considerado medio de prueba en materia civil y no en asuntos penales, sobre todo entendiendo que Colombia se estructura en un sistema de libertad probatoria, donde lo que debe primar sin desconocer las condiciones intrínsecas de la prueba- es que el elemento probatorio sea relevante para alcanzar grados de confirmación o probabilidad de las proposiciones presentadas por las partes al juzgador.

En este punto, se recuerda que en el ejercicio de la autonomía privada y la libertad de autorregulación de intereses que se suscitan en la celebración de negocios jurídicos, no es extraño señalar que en ocasiones, los particulares sin vulnerar normas de orden público, celebran contratos con apariencia de realidad, como si fueran actos que realmente existieran, siendo ello lo contrario o incluso de manera pública se les reviste con la apariencia de otro negocio jurídico; en ambos casos, se produce una distorsión entre la voluntad declarada y la voluntad real, de manera tal que confabuladas las partes intervinientes, en razón de un convenio ordinariamente mantenido en secreto y materializado con sigilo y precaución, pretenden restarle eficacia a la declaración de voluntad exteriorizada.

Por lo tanto, pese a que el negocio reúna externamente las condiciones de validez, éste no constituye ley para las partes ya que la actuación realizada no las ata, sino que la verdadera voluntad interna es la llamada a regir sus relaciones, razón por la cual la jurisprudencia de la Corte Suprema de Justicia, 
desentrañando el contenido del artículo 1766 del Código Civil, habilitó en el ordenamiento patrio la acción declarativa de simulación, a fin de permitir que los terceros, o las partes que se vean afectadas por el acto aparente, puedan desenmascarar tal anomalía en defensa de sus intereses, y obtener el reconocimiento jurisdiccional de la realidad oculta, en aras de combatir el acuerdo evasivo.

el actual ordenamiento procesal civil dejó a la libre apreciación del juzgador, con específicas excepciones, la ponderación razonada del mérito de las pruebas de acuerdo con las reglas de la sana crítica, de lo cual fluye que en materia de pretensión simulatoria y para su exitoso ejercicio, pueden las partes o los terceros, acudir a toda clase de medios de convicción, teniendo en cuenta la audacia con la que los contratantes suelen actuar para disfrazar el acto maquinado, aun cuando en la realidad jurídica la prueba indirecta es la más socorrida, particularmente la indiciaria, dada la dificultad probatoria que campea en esta materia.

Con el fin de respetar el ejercicio de valoración probatoria de los operadores judiciales, y teniendo en cuenta la necesidad de sustentar la apreciación de los medios probatorios aducidos, la doctrina y la jurisprudencia han hecho un enorme esfuerzo para sentar algunas pautas demostrativas para guiar la tarea investigativa de la simulación; unas derivadas de las condiciones personales de los contratantes, otras para infirmar el objeto del contrato y su ejecución, y otras más de la actitud observada por los simuladores.

De esta forma, cuando un acto aparente afecta los intereses patrimoniales de una de las partes o de un tercero, surge la acción declarativa de simulación como remedio para descubrir la verdadera intención entre las partes, cuya discusión judicial impone un cotejo probatorio, en orden a establecer cuál es el real contenido del acuerdo, propósito para el cual, señala la sentencia 5727 proferida el 17 de octubre de 2000, los interesados pueden utilizar todos los medios de prueba pertinentes, máxime el grado de ocultamiento con el que se forjan este tipo de actos simulados. Por este motivo, no le es dable al legislador, establecer una tarifa legal, que restrinja el libre empleo de la prueba en esta materia (Corte Suprema de Justicia, Sala de Casación Civil, sentencia No. 5727 del 17 de octubre de 2000, con ponencia del magistrado Carlos Ignacio Jaramillo Jaramillo).

De esta manera, por medio de la acción de simulación, se intenta privar de los efectos que le son propios a una declaración de voluntad, pues si no existe negocio jurídico y se aparenta su existencia, lo que se pretende es que no se altere la situación patrimonial que se encontraba antes de la celebración del mismo, evento conocido con el nombre de simulación absoluta; y, si se cobija bajo la forma propia de un contrato otro diferente, entonces se configura la simulación relativa, en cuanto a la naturaleza misma del contrato, respecto del contenido o de los sujetos. Restringir el empleo libre de la prueba, en 
efecto, no estaría en consonancia con el propósito de facilitar la comprobación del acto simulador, hijo de la audacia y del secreto de sus artífices, encaminado a desdibujar la realidad jurídica.

La dificultad probatoria en la simulación ha sido reconocida por la Sala de Casación Civil de la Corte Suprema de Justicia, y se ha indicado de manera frecuente que el juzgador debe acudir la mayoría de las veces a la prueba indirecta, siendo esta en muchos casos el único instrumento para vislumbrar la verdadera intención de los contratantes, tal como lo dice la sentencia del 22 de febrero de 2000:

[... ] Esta Corporación ha señalado en numerosa jurisprudencia que dada la dificultad probatoria en materia de simulación, donde los contratantes generalmente toman las medidas adecuadas para impedir que el verdadero negocio salga a la luz, se acude en la mayoría de los casos a la prueba indiciaria, mediante la cual se logra, por inducción lógica, el resultado de dar por conocidos, con base en hechos firmemente acreditados en el proceso, otros que no lo están, lo que supone una labor crítica donde predomina ampliamente la actividad intelectual del juzgador, quien dentro de los límites señalados en la ley, libremente escoge los hechos básicos que le han de servir para formular la inferencia y deducir sus consecuencias (Corte Suprema de Justicia, Sala de Casación Civil, sentencia del 22 de febrero de 2000, bajo radicación No. 3205, con ponencia del magistrado Jorge Santos Ballesteros).

Con respecto a la valoración de la prueba indiciaria, la Sala de Casación Civil de la Corte Suprema de Justicia, instituyó que esta actividad se encuentra en cabeza de los operadores judiciales, los cuales deben, en primera instancia, demostrar los hechos indicadores, y posteriormente cuando los indicios hacen parte del acervo probatorio, calificar su gravedad, concordancia y convergencia, en relación con las demás pruebas allegadas al proceso.

La Corte Suprema de Justicia, en su Sala de Casación Civil, en sentencia del trece (13) de agosto de dos mil diecinueve (2019), con ponencia del Magistrado Aroldo Wilson Quiroz Monsalvo, preceptúa lo siguiente en torno a los indicios dentro de un caso de nulidad de testamento abierto:

La apreciación de los indicios comprende una actividad múltiple, que consiste, por un lado, en el examen de los hechos indicadores que brotan de los medios de prueba, y, por el otro, en la deducción o inferencia que con base en ellos permite arribar a otros hechos indicados, como fruto de una operación mental lógica del juzgador de instancia, la cual, en línea de principio, se entiende enmarcada dentro de la autonomía y soberanía que lo asisten, desde luego, salvo en aquellos eventos en que haya incurrido en un error mayúsculo o superlativo, esto es, cuando aparezca una ostensible contraevidencia, ya sea porque sin estar acreditado un hecho indicador es tenido como tal, o estándolo es pasado por alto, o porque, con desprecio de los dictados del sentido común, 
deja de reconocer o admite, respectivamente, la comprobación de un hecho indicado, haciendo caer así su juicio de valor en el terreno de lo absurdo o irracional.

(...). En esta materia, tiene dicho la doctrina jurisprudencial que el error de hecho emerge cuando el Juez establece la existencia de un hecho desconocido a partir de un hecho indiciario que no fue probado, o si estándolo ignoró su presencia, o admitiéndolo le negó la posibilidad de generar conocimiento de otro hecho, o provocó uno con desdén hacia la prueba que obra en el expediente, sin perjuicio, por supuesto, de las fallas inherentes a su apreciación, vinculadas a la concordancia y convergencia que debe existir entre unos y otros, así como entre todos ellos y los restantes medios de prueba recaudados.

En este orden, para que se configure la prueba indiciaria se requiere el hecho indicador (que debe acreditarse en el proceso) y la inferencia extraída de este acerca de una situación distinta (hecho indicado), la cual realiza el juzgador. De allí que la errada ponderación fáctica de un indicio puede emanar de la incorrecta apreciación de los hechos indicadores -ya sea por preterirse los efectivamente demostrados, por desfigurárseles al punto de hacerles perder los efectos que de ellos se derivan o por suponerse unos inexistentes-; así como porque el raciocinio del sentenciador, al deducir el hecho indicado, contradiga abierta y notoriamente el sentido común o las leyes de la naturaleza. En esta tarea es menester distinguir entre las diversas clases de indicios: i) el necesario, aquel hecho que de manera inequívoca deja ver el indicado; y, ii) el contingente, suceso demostrado pero que puede tener varias causas, lo que da lugar a la subdivisión entre graves, leves y levísimos, según corresponda al grado de persuasión que represente.

\section{El Indicio en el Ordenamiento Penal Colombiano}

En el proceso penal colombiano, regido por la ley 906 de 2004, no se define ninguna postura frente al indicio, pues no se encuentra enlistado dentro de los medios de conocimiento. Vale destacar que dentro de la ley 600 de 2000, es decir, el Código de Procedimiento Penal inmediatamente anterior sí aparecía el indicio como medio de prueba.

La jurisprudencia nacional ha establecido una serie de derroteros acerca de la prueba indiciaria con independencia de la ley procesal penal vigente, por lo que se hace imperioso comenzar este recorrido con la sentencia del 27 de noviembre de 1996, en la cual se detalla cómo se debe censurar el análisis de los hechos indicadores o de las inferencias lógicas que devienen de los primeros, de esta manera se crea un precedente, el cual con el paso del tiempo se ha desarrollado con más especificaciones, pero en sí, este es el fundamento que se ha mantenido (Corte Suprema de Justicia, Sala de Casación Penal, sentencia de 27 de noviembre de 1996, con ponencia del magistrado Fernando Arboleda Ripoll). 
Teniendo en cuenta que aún siguen siendo revisados, en sede de casación, procesos tramitados bajo la égida de la Ley 600 de 2000, en sentencia del 16 de marzo de 2016, se reconoció el poder demostrativo de la prueba indiciaria para fundamentar una condena, especialmente porque este medio se encontraba taxativamente detallado dentro del catálogo de posibilidades probatorias ofrecidas por el anterior estatuto procesal, es decir la ley 600 de 2000:

Nada impide que la sentencia de condena se soporte en prueba indiciaria, siempre que su valoración conjunta, integral y articulada, ceñida a los criterios previstos en el artículo 287 de la Ley 600 de 2000, arroje certeza sobre la materialidad del delito y la responsabilidad de la persona investigada (Corte Suprema de Justicia, Sala de Casación Penal, sentencia del 16 de marzo de 2016, con ponencia del magistrado Eugenio Fernández Carlier, bajo la radicación No. 40461).

En cuanto a la construcción de los indicios, ha establecido la Corte, que en ocasiones de una misma fuente de prueba pueden derivarse diferentes indicios, siempre y cuando las inferencias que de ellos emanen, respondan a las máximas de la experiencia aplicables en cada caso:

El indicio es solamente eso, el resultado de una inferencia realizada a partir de un hecho conocido y debidamente acreditado por uno o varios medios de prueba, que nos permite establecer con gran probabilidad otro hasta ese momento desconocido, pudiendo suceder que, a partir de una misma fuente de prueba, se puedan establecer varios hechos que a su vez pueden dar lugar a la construcción de otros tantos indicios.

Así, por vía de ejemplo, cuando a partir de un testimonio de una persona que goza de gran credibilidad, pues en ella no se evidencia ningún motivo que permita sugerir que falta a la verdad, sea por interés frente al caso o por animadversión respecto de alguna de las partes, se acredita que Paulo fue visto salir corriendo con un arma de fuego en la mano de la habitación en donde momentos después se encontró una persona muerta a consecuencia de varios disparos, de ese medio de convicción se podrían inferir varios hechos, a saber: (i) que Paulo estuvo allí (indicio de presencia), que al portar el arma de fuego con ella pudo haber disparado contra la víctima (indicio de tenencia de un arma de fuego) y que al salir velozmente de allí sólo pretendía la impunidad (indicio de huida), a partir de lo cual a primera vista se podría llegar a pensar, como lo hace el recurrente, que son varios los indicios construidos a partir de un solo hecho indicador, y que una tal forma de razonar se encuentra prohibida por el ordenamiento procesal penal, cuando lo cierto es que en honor a la verdad se trataría de varios indicios establecidos a partir de hechos distintos, pese a que todos ellos provienen de una misma fuente de prueba. (Corte Suprema de Justicia, Sala de Casación Penal, sentencia del 8 de junio de 2016, con ponencia del magistrado José Francisco Acuña Vizcaya, bajo la radicación No. 41427). 
Se recuerda que uno de los cambios más importantes y polémicos introducido por la ley 906 de 2004, con relación al indicio fue su eliminación de la lista de medios de prueba establecidos por la normatividad, en ese sentido, la Corte ha precisado que aun cuando no esté taxativamente reconocido, las inferencias lógico jurídicas a través de operaciones indiciarias no se encuentran prohibidas o proscritas (Corte Suprema de Justicia, Sala de Casación Penal, sentencia del 29 de noviembre de 2017, con ponencia del magistrado Luis Antonio Hernández Barbosa, bajo la radicación No. 48690).

Posteriormente, el 16 de mayo de 2018 la Corte nuevamente se refiere a los hechos indicadores y su importancia en la estructuración de situaciones fácticas con el fin de que se elabore una conclusión fuerte sobre el dato inferido, la Sala lo plantea así:

En cuanto a la utilización de hechos indicadores a partir de los cuales se colijan inferencias con miras a establecer el hecho jurídicamente relevante, la Corte ha dicho que "se debe prestar especial atención a la demostración de los hechos indicadores o datos que sirven de base a ese proceso, para evitar el riesgo de construir argumentos cuya solidez sea solo aparente por estar estructurados sobre realidades fácticas que no tienen el suficiente respaldo probatorio (ídem)."

Lo precedente sin desconocer la importancia de la explicación que media entre los hechos indicadores y la conclusión del hecho jurídicamente relevante, paso intermedio que puede materializarse a través de una máxima de la experiencia, una regla técnica o una ley científica, o por la multiplicidad de datos convergentes y concordantes que doten a la conclusión de la suficiente fuerza sobre el dato inferido. (Corte Suprema de Justicia, Sala de Casación Penal, sentencia del 16 de mayo de 2018 con ponencia del magistrado José Francisco Acula Vizcaya, bajo la radicación 50723).

Actualmente, la última sentencia de esta Corporación sobre la cual se tiene conocimiento y que aborda el tema del indicio, es del 12 de febrero de 2020, en concreto, sobre el valor suasorio de este medio de prueba en cuanto a la inferencia que pueda construirse entre el hecho indicador y el indicado, ratificándose nuevamente la necesidad de que la deducción obtenida goce de un alto margen de probabilidad:

Por otro lado, es incontrovertible que la construcción inferencial elaborada por el juzgador para sustentar la condena no tiene el mérito probatorio suficiente para ello, y en tal virtud, el fallo atacado contravino el principio de razón suficiente.

Recuérdese que el valor demostrativo de la deducción indiciaria depende principalmente de la relación de mayor o menor probabilidad (establecida desde la sana crítica) que exista entre el hecho indicador y el indicado; si éste, a la luz de la lógica, la experiencia o la ciencia, se explica necesariamente o en alto grado de probabilidad a partir de aquél, 
la inferencia tendrá un peso suasorio significativo. En contraste, si es poco probable que el hecho indicado se siga del indicador, o bien, si la ocurrencia de aquél puede explicarse razonablemente por una o más causas distintas, el mérito de la construcción indiciaria resultará debilitado. (Corte Suprema de Justicia, Sala de Casación Penal, sentencia del 12 de febrero de 2020 con ponencia del magistrado José Francisco Acuña Vizcaya, bajo la radicación No. 51384).

Del anterior recorrido jurisprudencial, se colige que en vigencia del decreto 2700 de 1991 y la ley 600 de 2000, el indicio era considerado taxativamente como prueba en el proceso penal. De esta manera, fueron probadas infinidades de conductas delictivas, mostrando su existencia o inexistencia. En este escenario se suscitaron innumerables controversias, tanto en la doctrina como al interior de las actuaciones, pues la construcción del indicio, a pesar de estar regida por las reglas de la experiencia, lo que supondría un concepto objetivo, podría verse afectada por la subjetividad del juzgador, y de ese modo, no cumpliría con la finalidad de generar certeza, sino que suscitaba incertidumbre con respecto a señalar si el juez valoraba o no el hecho indicador de acuerdo con las reglas de la sana crítica.

Esta subjetividad traería como consecuencia que el funcionario incurra en errores de juicio, lo que desencadenaría una gran controversia al interior del litigio y esto se debe a que la persona encargada de apreciar la prueba es un ser humano que, por naturaleza, puede cometer yerros que pondrían en peligro el normal desarrollo del proceso. Por otra parte, estos errores sólo se evidenciarían con la decisión, pues es ahí donde se conocerá la posición del juez con relación a los indicios estructurados.

Hay que agregar que la parte inconforme con la conclusión proveniente de la operación lógica, es decir, la que cree que se incurrió en error, sólo tiene oportunidad de alegarlos al interponer recurso de apelación contra la sentencia y el extraordinario de casación, si es el caso. El recurrente debe ubicar dónde se encuentra el error, si en las pruebas que sirvieron para acreditar el hecho indicador, o en el proceso intelectual que implica la inferencia. Si los errores se encuentran en las pruebas que sirvieron para acreditar el hecho indicador, debe señalarse, si fue de hecho o de derecho. Si estos están en la inferencia lógica, siempre serán de hecho por la aplicación de las reglas de la sana crítica (Parra, 2005).

Al respecto vale decir que, además de tener que esperar la apreciación de la prueba indiciaria en la respectiva sentencia, debe cumplirse con el requisito fundamental que la Corte Suprema de Justicia ha exigido, es decir, explicar la clase de error del cual se adolece en la providencia respectiva. Desde esta óptica, solo se tendrá respuesta en el fallo del recurso que se hubiere interpuesto. Una vez más, se denota que esta prueba trae consigo una infinidad de consecuencias jurídicas que, generan incertidumbre a los sujetos procesales tanto al momento de ser construidas como al ser valoradas. 
Es necesario aclarar que, de conformidad con las providencias examinadas proferidas en el marco de la ley 906 de 2004, y verificado que el indicio desaparece como medio probatorio taxativo, aún sigue siendo construido y valorado en las sentencias de manera reiterada, esto por cuanto se considera que las inferencias permanecen, y son comunes a todos los medios de conocimiento, en especial a las evidencias físicas y elementos materiales probatorios, los cuales, por sí solos, no generan convicción sobre hecho alguno. En este caso, estos fungen como hechos indicadores que necesitan, de manera obligatoria, los otros requisitos indiciarios.

\section{Conclusiones}

El proceso se desata en una serie de actuaciones encaminadas no solo a solucionar el conflicto presentado por los interesados sino, además, la búsqueda de la verdad y la reconciliación. De ahí a que se hubiera forjado toda una estructura que pretende evacuar las pretensiones y excepciones de las partes en aras de impartir una pronta y cumplida justicia. No obstante, ningún trámite podría llegar a buen fin sin la prueba, que proporciona los elementos de convicción correspondientes para que pueda emitirse una decisión.

El derecho probatorio, como elemento inescindible del derecho procesal ha construido un andamiaje con respecto a los medios que pueden ser aportados por las partes y valorados por el juzgador, a la luz de la sana crítica, en tal sentido, el avance de los tiempos ha afianzado aquellos que desde antaño han sido empleados y del mismo modo, ha perfeccionado los que se modernizan a diario.

De lo antedicho se desprende que el testimonio, la confesión, el juramento, la inspección judicial, el dictamen pericial y el indicio se han mantenido en las codificaciones procesales colombianas tanto del orden penal como civil, salvo en la ley 906 de 2004, en la cual se proscribió el indicio como medio de prueba, lo que no ha sido obstáculo para que por vía jurisprudencial se reconozca que las inferencias indiciarias continúan vigentes y ostentan mérito suasorio para sustentar ciertas determinaciones.

El indicio como prueba indirecta ha sido ampliamente empleado históricamente, incluso la literatura lo menciona en muchas narraciones como quiera que, por su carácter circunstancial ha permitido revelar incontables misterios a través de sendas deducciones, por ello hasta la fecha su utilización no se limita al ámbito procesal, sino que se extiende a actividades cotidianas en las que el ciudadano desprevenido emplea el término para sustentar aseveraciones que no tienen respaldo en otras evidencias.

Se ha discutido mucho su naturaleza autónoma, dada la confusión de algunos autores con respecto a este medio de prueba con la presunción e incluso con 
el objeto de prueba, sin embargo, luego del estudio realizado se colige que evidentemente goza de una fisonomía propia, que se extrae de los elementos que la conforman los cuales están delimitados, es decir, el hecho indicador, la regla o máxima de la experiencia, el hecho indicado y el nexo causal entre el hecho indicador y el hecho indicado, todos con su estructura lógica definida, dependiente del análisis y ejercicio mental de quien construye el indicio.

En materia civil, este medio de convicción continúa siendo una de las pruebas reconocidas por el Código General del Proceso, como quiera que se replicó la reglamentación del Código de Procedimiento Civil, pero es importante resaltar que en uno de los procesos en los cuales se denota su vital injerencia es en el marco de la acción de simulación, teniendo en cuenta que, por los artificios creados para ocultar la real voluntad de las partes, no es común que se conozcan soportes documentales o de otra índole.

En contrapartida, la ley 906 de 2004 no incorporó en su catálogo de pruebas el indicio, lo que no implicó que se prescindiera de este en algunas actuaciones, presentado en algunas normas como inferencia razonable, la cual es empleada para sustentar decisiones de audiencias de audiencias preliminares, como la de imposición de medida de aseguramiento. En consecuencia, no es ajena a la práctica penal su empleo, dado que en estas actuaciones este es uno de los principales insumos para los jueces de control de garantías.

El indicio como se ha expuesto continúa entonces participando en las actuaciones, lo que en no pocas ocasiones ha suscitado innumerables controversias relacionadas con su construcción, pues algunos funcionarios se limitan a mencionarlos y no a explicitar el procedimiento lógico llevado a cabo para su estructuración. De ahí a que la jurisprudencia enfatice en la necesidad de que los operadores jurídicos puntualicen uno a uno sus elementos para que puedan ser debidamente atacados por las partes, pues de lo contrario se vulneraría el derecho de contradicción. En las audiencias preliminares debe emplearse con rigurosidad la técnica indiciaria para evitar injusticias, teniendo en cuenta que en ese escenario se debaten delicados temas, tales como la limitación a los derechos a la libertad, intimidad, propiedad y demás garantías fundamentales, intrínsecas al ser humano.

A su vez, y como se explicó anteriormente en este trabajo, ninguna circunstancia fáctica es un indicio por sí mismo, se hace menester conectarlo con otra realidad. Y es que no siempre un hecho puede acreditarse mediante prueba directa, nótese, por ejemplo, como los hechos internos requieren un razonamiento indiciario, toda vez que no son observables, se necesita inferirlos a partir de sus manifestaciones externas, como es el caso de las intenciones, las emociones, las creencias y otros hechos psicológicos, como la buena o mala fe. 
Se considera de tal manera, que la trascendencia de los indicios no se puede limitar a la prueba de los hechos internos, sino también a la prueba de los hechos externos, en el entendido que dentro de lo que hoy en día la doctrina denomina razonamiento probatorio, se hace de vital importancia tener grados de probabilidad altos, que contribuyan a niveles mayores de corroboración de la hipótesis que se quiere probar.

En este orden de ideas, la prueba indiciaria puede servir como complemento a la prueba directa, sin necesidad de excluirla o de subvalorarla como medio de convicción, sobre todo porque se debe tener presente, que mientras más elementos soporten o apoyen a la hipótesis judicial, mayor será su grado de corroboración frente al establecimiento de la verdad en torno a las proposiciones-hechos- presentadas por las partes dentro del proceso.

\section{REFERENCIAS}

Arenas, J. (2003). Pruebas penales. Ediciones Doctrina y Ley Ltda.

Azula, J. (1993). Manual de Derecho Procesal Civil. Teoría General del Proceso Tomo I. Editorial Temis.

Bello, H. (2016). Tratado de Derecho probatorio. Tomo II. Editorial Ibáñez

Bueso, M. (2001). De las presunciones e indicios. En: Anuario de la Facultad de Derecho.

Carrillo de la Rosa, Y., \& Luna Salas, F. (2021). Aproximaciones conceptuales al razonamiento de los hechos, la verdad y la prueba. JURÍDICAS CUC, 17(1), 173210. https://doi.org/10.17981/juridcuc.17.1.2021.07

Concha, J. (1983). Elementos de pruebas judiciales. Librería Americana.

Contreras, R. (2015). La prueba indiciaria. En: Adame López, Ángel Gilberto (Coord.) Homenaje al doctor Bernardo Pérez Fernández del Castillo. Instituto de Investigaciones Jurídicas de la Unam.

Corte Suprema de Justicia, Sala de Casación Civil, sentencia de 17 de octubre de 2000, con ponencia del magistrado Carlos Ignacio Jaramillo, radicado No. 5727.

Corte Suprema de Justicia, Sala de Casación Civil, sentencia de trece (13) de agosto de dos mil diecinueve (2019), con ponencia del Magistrado Aroldo Wilson Quiroz Monsalvo. SC3140-201 9 Radicación No. 05001-31-10-009-2008 00867-0 1

Corte Suprema de Justicia, Sala de Casación Civil, sentencia del 12 de marzo de 1974, publicada en Jurisprudencia y Doctrina Tomo III.

Corte Suprema de Justicia, Sala de Casación Civil, sentencia del 22 de febrero de 2000, con ponencia del magistrado Jorge Santos Ballesteros, radicado No. 3205. 
Corte Suprema de Justicia, Sala de Casación Civil, sentencia Sc5418 de 11 de diciembre de 2018, con ponencia del magistrado Octavio Augusto Tejeiro Duque, radicado No. 05042-31-84-001-2002-00107-01.

Corte Suprema de Justicia, Sala de Casación Penal, sentencia de 18 de marzo de 2015, con ponencia del magistrado Eugenio Fernández Carlier, radicado No. 33837.

Corte Suprema de Justicia, Sala de Casación Penal, sentencia de 16 de marzo de 2016, con ponencia del magistrado Eugenio Fernández Carlier, radicado No. 40461.

Corte Suprema de Justicia, Sala de Casación Penal, sentencia de 16 de mayo de 2018, con ponencia del magistrado José Francisco Acuña Vizcaya, radicado No. 50723.

Corte Suprema de Justicia, Sala de Casación Penal, sentencia de 12 de febrero de 2020 con ponencia del magistrado José Francisco Acuña Vizcaya, radicado No. 51384.

Corte Suprema de Justicia, Sala de Casación Penal, sentencia de 29 de noviembre de 2017, con ponencia del magistrado Luis Antonio Hernández Barbosa, radicado No. 48690.

Corte Suprema de Justicia, Sala de Casación Penal, sentencia de 4 de mayo de 1997, con ponencia del magistrado Jorge Aníbal Gómez Gallego, radicado No. 9858.

Corte Suprema de Justicia, Sala de Casación Penal, sentencia de 8 de junio de 2016, con ponencia del magistrado José Francisco Acuña Vizcaya, radicado No. 41427.

Corte Suprema de Justicia, Sala de Casación Penal, sentencia del 27 de noviembre de 1996, con ponencia del magistrado Fernando Arboleda Ripoll.

Corte Suprema de Justicia, Sala de Casación Penal, sentencia SP1786 de 23 de mayo de 2018, con ponencia del magistrado Eugenio Fernández Carlier, radicado No. 42631.

Corte Suprema de Justicia, Sala de Casación Penal, sentencia SP9379 de 28 de junio de 2017, con ponencia de la magistrada Patricia Salazar Cuéllar, radicado No. 45495.

Cuadros, R. (2013). Sofística, retórica, y filosofía. En: Praxis filosófica, (37).

Dellepiane, A. (1997). Nueva teoría de la prueba. Editorial Leyer.

Devis, H. (2012). Teoría general de la prueba. Editorial Temis.

Díaz De León, M. (2002) "La prueba indiciaria”, en Quinceno Álvarez, Fernando, Indicios y presunciones. Editorial Jurídica Bolivariana.

Döhring, E (2008). La prueba. Práctica y apreciación. La investigación del estado de los hechos en el proceso. Editorial Leyer. 
Ellero, P. (1953). Juicios criminales. Instituto editorial Reus.

Fernández, M. (2005). Prueba y presunción de inocencia. Editorial Iustel Portal Derechos, S.A.

Framarino Dei Malatesta, N. (2002). Lógica de las pruebas en materia criminal. Editorial Temis.

García, J. (1982) Razonamiento silogístico e interpretación de premisas: un estudio evolutivo. En: Inferencia y aprendizaje, (19-20).

Gascón, M. (2010). Los hechos en el derecho. Bases argumentales de la prueba. Marcial Pons.

Ginzburg, C. (1999). Mitos, emblemas, indicios. Morfología e historia. Gedisa.

Gorphe, F. (2004). Apreciación judicial de las pruebas. Editorial Temis.

Leone, G. (1963). Tratado de derecho procesal penal, Tomo II. Editorial EJEA.

Lessona, C. (2006). Las presunciones en el derecho probatorio. Editorial Leyer.

Londoño, M. (2006). Los indicios conductuales en el proceso civil. En: Opinión Jurídica, 5 (10).

Luna Salas, F. (2018). El mito del cientificismo en la valoración de la prueba $\begin{array}{lllll}\text { científica. } & \text { JURÍDICAS } & \text { 119-144. }\end{array}$ https://doi.org/10.17981/juridcuc.14.1.2018.06

Mittermaier, C. (2005). La prueba en materia criminal. Editorial Leyer.

Muñoz, L. (1997). Técnica probatoria. Estudios sobre las dificultades de la prueba en el proceso. Editorial Temis.

Muñoz, L. (2016). La prueba de indicios en el proceso judicial. Análisis para juristas, detectives, periodistas, peritos y policías. Editorial Wolkers Kluwer, España S.A.

Pabón, G. (2007). Lógica del indicio en materia criminal Tomo I. Editorial Ibáñez

Parra, J. (2005). Tratado de la prueba judicial indicios y presunciones. Editorial Ediciones Librería del Profesional.

Reyes, Y. (1989). La prueba indiciaria. Ediciones Reyes Echandía Abogados Ltda.

Rocha, A. (1990). De la prueba en derecho. Biblioteca Jurídica Dike.

Roxin, C. (2000). Derecho procesal penal. Editores del puerto.

Shakespeare, W. (2000) Otelo. Ediciones B. 
Saza Pineda, J. F., \& Luna Salas, F. (2020). Vicisitudes del proceso monitorio en Colombia. Revista Jurídica Mario Alario D’Filippo, 12(24), 302-322. https://doi.org/10.32997/2256-2796-vol.12-num.24-2020-2677

Silva, V. (2002). Presunciones e indicios. En: Quinceno Álvarez, Fernando, Indicios y Presunciones. Editorial Jurídica Bolivariana.

Taruffo, M. (1970). Studi sulla rilevanza della prova. Padova: Cedan.

Tirado, J. (2013). Curso de pruebas judiciales, Tomo II. Ediciones Doctrina y Ley.

Zavala, J. (1989). El proceso penal Tomo II. Editorial Edino. 